First Peoples Child \& Family Review

An Interdisciplinary Journal Honouring the Voices, Perspectives, and Knowledges of First Peoples through Research, Critical Analyses, Stories, Standpoints and Media Reviews

\title{
Why is Adoption Like a First Nations' Feast?: Lax Kw’alaam Indigenizing Adoptions in Child Welfare
}

\section{Maria Bertsch and Bruce A. Bidgood}

Volume 5, Number 1, 2010

URI: https://id.erudit.org/iderudit/1069066ar

DOI: https://doi.org/10.7202/1069066ar

\section{See table of contents}

\section{Publisher(s)}

First Nations Child and Family Caring Society of Canada

\section{ISSN}

1708-489X (print)

2293-6610 (digital)

Explore this journal

\section{Cite this article}

Bertsch, M. \& Bidgood, B. (2010). Why is Adoption Like a First Nations' Feast?: Lax Kw'alaam Indigenizing Adoptions in Child Welfare. First Peoples Child \& Family Review, 5(1), 96-105. https://doi.org/10.7202/1069066ar
Article abstract

Have you ever wondered about how to be culturally-sensitive in adoption approaches with Aboriginal people? Have you wanted ideas on how to more effectively engage First Nations adoptive-parents? Did you consider how leadership for social workers could assist in adoption outcomes for Aboriginal children? This article chronicles a study of the adoption experiences of the members of a First Nations community in Northwestern British Columbia, Canada. The results indicated that despite an overwhelmingly negative history with the adoptions and child protection system, many First Nations people are not only open to adoption but perceive it as an integral part of their traditional parenting practices. There is an overarching desire to have children who have been previously adopted outside the community returned to their hereditary lands. A series of recommendations for a more culturally-sensitive adoption practice were identified including: 1) improved information, 2) on-going community-government consultation, 3) cultural preservation, 4) social work training, and 5) government policy changes. The article will encourage curiosity regarding social work leadership and how this framework can be instrumental when working with Aboriginal culture. The implications of the study for the role of social workers as leaders in the creation of a new, culturally-sensitive adoption practice are discussed.
This document is protected by copyright law. Use of the services of Érudit (including reproduction) is subject to its terms and conditions, which can be viewed online.

https://apropos.erudit.org/en/users/policy-on-use/ 


\title{
Why is Adoption Like a First Nations Feast?: Lax Kw'alaam Indigenizing Adoptions in Child Welfare
}

\author{
Maria Bertsch ${ }^{\mathrm{a}}$ and Bruce A. Bidgood ${ }^{\mathrm{g}}$
}

\begin{abstract}
a M.A. (Leadership: Royal Roads University), R.S.W., B.S.W. has been employed as a government adoption worker for the past six years. She has also worked with child protection clients, day care clientele, street youth, and volunteers with the Abbotsford Police. She has also served as a human resources consultant for the Musqueam Nation, a private management consultant and an owner/operator of a private business. Her research investigated the experiences and recommendations for adoption practice with the First Nations community members of Lax Kw'alaams located in Northwest BC. Maria has presented her research to various groups and provincial conferences.

b B.A., M.S.W., Ph.D., Associate Professor, School of Social Work, University of Northern BC, NW campus. Dr. Bidgood is an Associate Professor in the School of Social Work at the University of Northern British Columbia. He also currently holds an appointment as an Adjunct Professor at the School of Business and Economics, Nipissing University. $\mathrm{He}$ is a federally-funded (SSHRC) researcher in the area of burnout and job satisfaction in both the public and private sectors. Dr. Bidgood also conducts research in the areas of child welfare, wife abuse, mental health, poverty, and food security.
\end{abstract}

\section{Introduction}

In Canada, Aboriginal adoption has a long and tumultuous history which has historically been known for taking Aboriginal children away from families and communities. A vast majority of these adopted Aboriginal children grew up with little connection to their birth family or their culture. No sooner had the residential "schools" begun to close their doors, then Aboriginal families and communities were subjected to a wave of state-initiated child

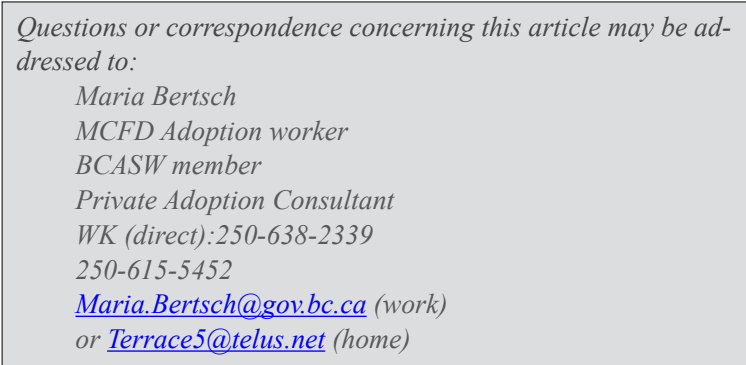

\begin{abstract}
Have you ever wondered about how to be culturally-sensitive in adoption approaches with Aboriginal people? Have you wanted ideas on how to more effectively engage First Nations adoptive parents? Did you consider how leadership for social workers could assist in adoption outcomes for Aboriginal children? This article chronicles a study of the adoption experiences of the members of a First Nations community in Northwestern British Columbia, Canada. The results indicated that despite an overwhelmingly negative history with the adoptions and child protection system, many First Nations people are not only open to adoption but perceive it as an integral part of their traditional parenting practices. There is an overarching desire to have children who have been previously adopted outside the community returned to their hereditary lands. A series of recommendations for a more culturally-sensitive adoption practice were identified including: 1) improved information, 2) on-going community-government consultation, 3) cultural preservation, 4) social work training, and 5) government policy changes. The article will encourage curiosity regarding social work leadership and how this framework can be instrumental when working with Aboriginal culture. The implications of the study for the role of social workers as leaders in the creation of a new, culturally-sensitive adoption practice are discussed.
\end{abstract}

apprehensions during the "60's scoop." The term "60's scoop" was coined to describe the seemingly random apprehensions of 'Indian children' by Provincial social workers who, on the slightest pretext, literally scooped children from reservations in order to 'save' them from poor living conditions (Timpson, 1995). Keewatin (2004) was more gracious in describing the "60's scoop" as "a clash in ideologies and adoption practices [which] contributed to Aboriginal children being taken from their homes" (p. 27). There was a belief that Aboriginal families were inferior and unable to care for their children; over 11,000 children were removed and placed in non-Aboriginal homes from the 1960s to the 1980s (Snow \& Covell, 2006). The inappropriateness and suffering of Aboriginal families and communities through 
First Peoples Child \& Family Review, Volume 5, Number 1, 2010

\section{Authors' Notes:}

This research was completed in partial requirement for the MA (Leadership) degree at Royal Roads University. The support of Ms. Anne Clayton, M.PA, Director of Provincial MCFD adoptions in Victoria, was pivotal to the project's success. Finally, this publication is only possible due to the courage and commitment of Lax Kw'alaam community members in northwestern BC.

decades of government intervention was acknowledged on June 11th, 2008 when the Prime Minister of Canada, Stephen Harper officially apologized, on behalf of the government of Canada, to the Indigenous, Inuit and Métis people.

Canada presently has a higher number of Aboriginal children in government care than in any other era in this country. Today, a disproportionate number of Aboriginal children enter government care, for example from 1995 to 2001 the number of Aboriginal children in care rose 71.5 per cent nationally (National Council of Welfare, 2007). Many of these children are placed in non-Aboriginal foster care without serious consideration about adoption by Aboriginal family or community members. Children who remain in foster care experience an average of sixteen different foster placements by the time they reach adulthood resulting in moves into different communities, families, cultures, schools, religions, and routines. After years of foster care, many Aboriginal children have little birth family or cultural connections left. With no family to return to, many Aboriginal youth 'age out' of foster homes only to become acquainted with the justice system (National ... etc, 2007).

\section{The sad fact remains: the state [government] as a parent notoriously lacks sensitivity and imagination in dealing with its children. Besides, bureaucracies are allergic to speed ... if contractors fast-track kids from foster homes into adoptive homes... this is a far cry from the status quo, which, in effect, rewards... keeping kids in no man's land (Webber, 1998, p. 209).}

Non-Aboriginal adoptive parents often argue that a permanent home for Aboriginal children is better than no permanent home at all. They believe that a safe and loving home, of any culture, can meet all of the needs of the Aboriginal adoptee; the result being a form of "colour-blindness".

Fogg-Davis (2002) disagrees stating that pretending not to notice colour is not the solution, reducing "racism is not colorblindness but a strong commitment to nondiscrimination as a moral principle that extends beyond equal-protection law into the realm of private racial choices" (p.9). The question of culturally- prioritizing adoption placements remains divisive between non-Aborignal adoptors and Aboriginal children, families and communities.
Research on the long-term effects of "culturally-foreign" adoptions [where Aboriginal children are adopted to nonAboriginal parents] are much less controversial. Sinclair (2007) revealed that 85 per cent of Aboriginal children adopted into non-Aboriginal homes break down during the child's adolescence resulting in the adoptee leaving their non-Aboriginal adoptive parents. One reason proposed for the high percentage of these adoption breakdowns is the lack of skills non-Aboriginal adopting parents have in supporting the Aboriginal child through systematic racism and the denigration of Aboriginal culture.

Is there really a paucity of caring Aboriginal families to adopt Aboriginal children? Research examining the preadoption views of perspective Aboriginal adoptive parents is scarce. A 2004 survey by the Dave Thomas Foundation (Dave Thomas Foundation for Adoption Canada, 2004), however, found that adoption is considered twice as often by Aboriginal people than by non-Aboriginal people. This begs the question as to why Aboriginal people remain under-represented as adoptive parents for Aboriginal children?

As a Caucasian adoption social worker in a small northern British Columbia (BC) community, the first author has observed that Aboriginal children display a unique desire for cultural connection throughout the process of adoption. A profound example of this involved watching a very young Aboriginal girl who, during her last visit with her nonAboriginal foster mother, stood silently, and stiffly beside her before being placed with Aboriginal parents. This same girl transformed into a happy, active and engaged girl when she was with her Aboriginal adoptive parents. She caressed the face of her Aboriginal adoptive parents. She began to crawl, laugh and relax around them. Prior to the adoption, the young girl was referred to the children's hospital for a full assessment for extensive behavioural problems in the foster home. After three months in her adoptive home, the girl quickly adjusted to her new Aboriginal adoptive parents and consequently professionals withdraw their assessment recommendations -the child no longer needed behavioural interventions services! Finally, the cultural significance of adoption is evident in the pride and symbolic significance that occurs when Aboriginal children are adopted back into their community; these are frequently celebrated with a community feast. 


\section{Why is Adoption Like a First Nations Feast?}

\section{Literature Review}

Historically, child welfare practice and policy has been rife with Eurocentric, mainstream assumptions and cultural misunderstandings. Contemporary legislation has attempted to redress these shortcomings. The Child, Family and Community Services Act (1996) and the Adoption Act (1996) prescribe that within child welfare practice, and particularly adoption, Aboriginal children must be given special attention in the planning of their cultural identity and heritage. In 1991, the BC legislation unanimously ratified the United Nations Convention on the Rights of the Child which holds that the right to cultural participation is fundamental to the best interest of the child. Despite the noble rhetoric, the current child welfare system continues to fail Aboriginal people through cultural genocide which perpetuates the "new Western colonization disease" (Crichlow, 2003, p. 89).

In 1847 , the senior levels of government and churches collaborated to begin the establishment of residential schools for Aboriginal children from 6 to 16 years of age (Bennett, Blackstock \& DeLaRonde, 2005, Keewatin, 2004). In 1857 it was law for an Aboriginal child to attend residential schools with the enactment of the Gradual Civilization Act (Assembly of First Nations, 2009). Over the next 149 years, more than 80 residential schools emerged in Canada and involved a gradual devolution of child welfare responsibility of thousands of Aboriginal children to church members. This practice was particularly pronounced in the province of $\mathrm{BC}$.

Nowhere in Canada was the instrument of the residential schools used more brutally and thoroughly than in British Columbia ... where the schools endured longer than anywhere else ... clerics mounted a concerted assault on the spiritual and cultural practices of the First Nation by taking away their most valuable and precious resource, their children (Fournier \& Crey, 1997, p. 50).

The period from 1950 to 1970 has frequently been termed the "Indian Adoption Era" in Canada (Halverson, Puig \& Byer, 2002, p. 323). These decades saw 20 to 50 per cent of Aboriginal children being removed from their homes and communities. The vast majority of these children were placed in non-Aboriginal homes (Halverson, et al., 2002). The Canadian Welfare Council and the Canadian Association of Social Workers provided recommendations through the Joint Submission for expansion of child welfare services to First Nation people on reserve, however funding for services did not follow (MacDonald \& MacDonald, 2007). Supervision of these displaced Aboriginal children was woefully inadequate; for example, in the 1960's social workers labored under enormous case loads -- nine social workers are reported to have held a case load for 179,000 reservation residents (Crichlow, 2003).

Another factor which is believed to have influenced the frequency of Aboriginal adoptions was the significant decline in the number of Caucasian infants available to Caucasian adopters. The proportion of Caucasian infants was 19 per cent of total adoptions in 1960 and dropped to 1.75 per cent in the early 1990's. The cry for infants was met by Aboriginal children being adopted into Caucasian homes.

To date, Canadian provinces continue to administer adoption programs with little or no consideration to the inherent rights of First Nation children. Canadian policy places the issue of adoption and First Nation children within a context of cross-cultural adoption, failing to recognize the contradictions in this practice. The issue is not about race, color or national origin; it is about the preservation of First Nation self-determination within a continuing colonial context (Carrier, 2005, p. 24).

Without federal involvement and funding, some authors' worry that adoption will become reduced to nothing more than one more program in the provinces, 'crisis-driven' child welfare system(s) (Riggs, 2003, p. 2). As it stands, there is a typical two year waiting list for perspective adoptive parents to complete their home study due to a shortage of social workers (Collier, 2002,p 55). With a mainstream-centered adoption screening process, long waiting lists for perspective adoptive parents, and limited Aboriginal support services, the result is an adoption practice which diminishes the ability of Aboriginal families to care for their children (Carriere, 2007).

Even if government funds were provided to increase Adoption workers, would this result in an adoption system which was more responsive/sensitive to Aboriginal peoples? Or, would this result in a perpetuation of existing practices including an unwillingness to consider perspective adoptive parents who do not fit into the typical mainstream categories?

Social workers have traditionally maintained an excessively narrow model of adoption practice. Traditionally, they have selected as potential adopters white, middle-class couples of conventional behavior and values with good material standards. Black and Native communities particularly have failed to meet such criteria (Bagley, Young \& Scully, 1993, p. 10).

In BC, the Ministry of Children and Family Development (MCFD) maintains a list of over 1,000 children waiting for adoptive homes. Many perspective adoptive parents hold fantasies and idealized notions of "charib-like" children who will complete their longed-for dream family. In reality, most of 
the children in care available for adoption have been scarred by maltreatment and years in the child welfare system.

\begin{abstract}
Today, the large majority of children requiring adoptive families do not carry the characteristics of most adoptersideal child. They tend to be older, have brothers or sisters with whom they hope to be placed, have multiple problems in terms of developmental delay or long term medical uncertainties and suffer the aftermath of abuse of all kinds. Furthermore, we now recognize how important it is to place children, whenever possible, in families who share their culture and ethnicity (Corbett, 2002, p 39).
\end{abstract}

Despite the many shortcomings of contemporary adoption policy/practice, there are some positive developments within the Aboriginal communities for the future of adoptive children. An example includes the first adoption agreement between the provincial government and the Aboriginal agency of Lalumiutul Smueem in Duncan, BC. This agreement was signed on Janurary 17th, 2008 which delegates responsibility for all aspects of adoption to the Cowichan tribes. The First Nation child welfare agencies have proved to be more effective than provincial agencies in finding ways to care for children within their communities (Wien, Blackstock, Laxley \& Trocme, 2007).

The MCFD North region and local First Nation communities have enjoyed 'cultural camps' or 'homecomings' which provide an opportunity for Aboriginal foster children to return to their hereditary land and meet family. Some Aboriginal families meet their children for the first time. Foster parents or social workers are encouraged to attend. The cultural camp usually involve Aboriginal foster children being the focus of celebration activities such as a community feast where children often receive a cultural gift and participate in Aboriginal dancing. The current research attempts to contribute to this growing body of progressive knowledge and practice by articulating a model of culturally-sensitive adoption which is grounded in the experiences of one Aboriginal community, Lax Kw'alaam.

\section{Methodology}

This research took place within MCFD's North region which encompasses more than one-half of the province's landmass, the province's largest geographic area, which includes approximately 51 Aboriginal bands. The Aboriginal children in care of the government in BC's north represent at least 76 per cent of all the children in care, many in non-Aboriginal foster homes.

This article seeks to "reveal unexamined assumptions and the ways in which people may be accepting explanations of the dominant cultural group who serve to oppress those without power" (Glesne, 2006, p. 16). This research was conducted to honor the cultural context of one northern BC First Nation coastal community, Lax Kw'alaam (also known as Port Simpson). Lax Kw'alaam is accessible by boat (ferry) or float plane which was utilized during this reserach. Through listening to the adoption experiences and views of the Lax Kw'alaam people, in a culturally comfortable setting designed in cooperation with their community members, ideas for a new adoption process emerged.

The research sought to answer the primary question: What to you believe the northern First Nation people need in order to adopt Aboriginal children who are in the care of MCFD? Through the exploration of Lax Kw'alaam adoption experiences, recommendations for recruitment of First Nation perspective adoptive parents were uncovered. The qualitative study utilized the concepts of Stringer's (1999) action research frameworks. Stinger (1999) believes only First Nation people can be cultural experts for their communities, and emphasizes collegial structuring, rather than hierarchical ones, with the goal of facilitating and supporting people, rather than directing and controlling them. To achieve a higher degree of relevance for outcomes, a culturally considerate research is argued to be more open to a First Nation worldview (Bennett, 2004).

A culturally sensitive group format, designed and facilitated by the Lax Kwalaam people, was termed "Circle groups." All participants were voluntarily selected by Lax Kw'alaam community leaders. Participant selection criteria included the following, a person; (a) free from past association with MCFD adoptions; (b) of First Nation ancestry who had lived in Lax K'Alaams or was presently living in the village; (c) at least 19 years of age; (d) able to express personal views in a small group; (e) identified by a Band worker as being curious about adoptions; and (f) believed to be free of mental illness. Results were obtained from two Circle groups $(\mathrm{N}=13)$; one group consisting of three males and four females was held with former Lax Kw'alaam community residents in the city of Terrace, and a second Circle group consisting of all females was held in Lax Kw'alaam. The age of participants was not recorded however, all participants were adults.

Informed consent was obtained through a variety of methods. A Consent form outlining the purpose of the study, voluntary nature of participation, confidentiality provisions and contact information for thesis supervisor and University was sent in advance to Lax Kwalaam leadership for the purposes of recruitment of participants. The same was read aloud during Circle group introductions and each member was given a copy of the letter for their individual reference. Individuals who agreed 
to participate had their consent recorded on audio tape and witnessed by the researcher and Circle group facilitator. ${ }^{1}$

\section{Ethics}

The ethics process involved cultural, professional and academic reviews. Academic approval was obtained from Royal Roads University Ethics review procedure (1999) including consultation with the University Aboriginal Coordinator. The research procedures were designed to conform to the Ethics of Research Involving Indigenous Peoples (Indigenous People's Health Research Center, 2004). Cultural review was provided by the local Aboriginal agency, Northwest Inter-Nation Family and Community Services Society (NIFCS) prior to community leaders being contacted. The study purpose and methods also received approval from Lax Kwalaam leadership. The research was also reviewed and approved by MCFD. Finally, the First Nation facilitator provided consultation on the research process, preliminary results and final document preparation and dissemination. The facilitator remains updated on research presentations to this day.

\section{Limitations and Scope of Research}

This research was limited by the researcher being a Caucasian, middle class social worker and the inherent cultural restrictions within such a perspective. The Circle groups were small enough to encourage conversation from all members but the MCFD ethics requirement disallowed those who had adoption experiences with MCFD. The Lax Kwalaam community was studied exclusively, and other communities and their members may have provided different results. The sample group was small. The geographical area of the northwest of $\mathrm{BC}$ could have been expanded to include First Nation people from a variety of locations. Future research with participants of other first nations communities in $\mathrm{BC}$ and throughout Canada would be valuable to ascertain whether the results observed here are illustrative of the experiences of other First Nations members. Additional research with those who have direct experience as adoptive parents or adoptees, but who were restricted from this research for reasons of confidentiality, would also prove valuable. Finally, research contrasting the experiences of First Nations people with custom adoptions versus non-Aboriginal adoption practices would prove advantageous.

\footnotetext{
1 Sherrie Haldane, M.S.W. and member of the Lax Kw'alaam community facilitated both Circle groups. She provided support, advice on methods, potential sources of bias in the analysis as well as nuances of culturally sensitive group practice for the Lax Kw'alaam Circle group participants.
}

\section{Themes}

The "circle groups" data were analyzed for recurrent substantive content using the principles identified by Stringer (1999) and Strauss \& Corbin (1998) which led to the identification of the following themes: 1) historical experiences with child welfare, 2) cultural loss within stranger care, 3) Aboriginal views about adoption and, 4) recommendations for indigenizing adoptions.

\section{Historical Experiences with Child Welfare}

\author{
"They took him completely away from his family"2
}

First Nation people have suffered serious losses on a community and individual level as a result of the past adoption actions. When asked about their adoption experiences, both Circle groups immediately responded by describing experiences with child protection. Participants recounted community loss when their children were taken without family being given information regarding how to contact their children or the area where the children were relocated. "There are a couple of cases ... where [social workers] came in, grabbed three children out of school, flew them in a plane, and nobody, nobody including the teachers ... contacted the parents to let them know what's happening." Negative past child protection practices and resulting encounters with social workers are stories sustained orally in community history. Years of witnessing the removal of children has yielded an over-arching sense of community grief.

Participants also identified an individual loss. When asked to describe adoption a Circle group participant stated, it was similar to "a person in authority, like the RCMP or Indian agent [who] comes, takes the children forcibly from the parents, and puts them in residential school ... the parents and family have no say." This grief, it is suggested, has a direct correlation with the views of adoption, a program associated with child welfare.

\section{Cultural Loss within Stranger-care}

\section{"The child is left with unresolved cravings"}

Participants compared the longings of children in strangercare similar to the feeling of a "craving," which is a multidimensional yearning of First Nation children who are placed in a non-First Nation homes. Cravings may be a desire for traditional foods, which became familiar to the unborn child as it was ingested by the birth mother.

Another craving was believed to take place from the child being deprived of cultural experiences. Several participants recounted observations of stranger-care providers who were reluctant to expose First Nation children to their culture. The 2 Quotations in italics within the Theme and Results and Recommendation Sections are those of Circle group participants. 
actions of stranger-care providers were interpreted as fear of First Nation culture and traditions. As an example, one participant viewed non-Aboriginal foster parents as trying to "protect the First Nation foster child from their First Nation traditions":

\section{... these people were non-native and they had one of our own kids from here. The dancers had a BBQ with salmon, fried bread, and our traditional foods ... that kid wanted to see, but they said 'no, no, no' everything was no. \\ Especially the fried bread, you can have fries, but you can't have fried bread ... yet while in the mother's womb, it was consumed ... they became accustomed to the taste so they know the taste.}

These cravings may encompass the feeling of community and family felt by the birth mother and transmitted to the unborn child or infant, but denied the child once they are in the government's care. One participant stated that children in care lose their family connections "because they are in the system too long". When the Lax Kw'alaam community representative is contacted from children in care, some of whom live around the world, the child or adult seeking family information has little to offer the community leadership -- family information is scarcely recorded and therefore not available years following. One participant spoke of a situation she knew of, a foster child sought to meet her biological parents. This request took social workers so long to work on, that both biological parents passed away before the foster child could meet them.

\section{"Hopefully, somewhere along the line, no matter where a child is adopted out, they will still maintain their cultural identity, because when they come to aging out category, that's the hard part."}

The general perception of outsiders caring for community children was discussed. When the non-Aboriginal caregivers negate valued cultural connections, "stranger-paid-caregivers" were viewed by participants as insufficient when compared to the provisions family members could offer a child within the context of their community. Another participant stated the children from their community "placed with non-native families [they] are the ones that we heard didn't work."

\section{Aboriginal Views about Adoption}

\section{"Indian Adoptions" are Alive and Well}

Traditionally, Aboriginal people sought Aboriginal 'adoptive' parents for their children when the situation warranted. Community members carried the conviction that sharing children promotes community strength, caring, and bonding (Crichlow, 2003; Keewatin, 2004, p. 26). Sharing children is part of the "traditional law, community standards, values and beliefs." Stories continue to be shared of children being given to others with honor bestowed on all parties. Collectively Circle group participants recognized these adoptions as "Indian adoptions," are acts of generosity from one family to another. When these children were cared for by the 'adopting' family, birth parents were acknowledged and often included. Several participants shared stories of a child who was identified as belonging to the adoptive family and yet knows their birth family. Typically children are given to those who do not have children or to those whose child has passed away.

She was pregnant and she felt sorry for her brother, so she said, 'when my baby is born, you can have the baby.' She when went into labor, both the brother and his wife were there... the baby turns out to be my Mom. This is Indian adoption ... because they were the ones that raised her up. But she never forgot her family.

Participants distinguished traditional adoptions involving tribal agreements, and custom adoption involving family agreements surrounding the child to be adopted. The practice of sharing children with those who care best care for them involves cultural titles and tribal positions along with birth family consultation. In lifelong planning for children, they are not estranged from their community, birth families or culture; as a result, First Nations languages have no traditional word for adoption (Bennett, et al, 2005, p. 24; L. Wells, personal communication, August 31, 2007).

The ethnocentric process of legally transferring parental rights is historically foreign. Traditional adoptions directly contrast legalized Western Adoption orders that decree children can be owned (Giesbrecht, 2004, p. 156). Lax Kw'alaam participant's spoke of 'Indian adoption' as an ancient, established, collaborative process for community children still in process today. The traditional or cultural adoptions are currently practiced in Lax Kw'alaam. One participant stated, "I think the whole of Canada doesn't recognize that we still have our own culture"

\section{Recommendations for Indiginizing Adoptions}

\section{Commitment Necessitates Action}

\section{"Is MCFD serious?"}

As participants began to discuss the possibilities of adopting children presently in care, the question of governmental commitment was raised. First Nation communities, especially those in an isolated location, already operate on scare resources. Simply having a good idea supported by research is inadequate within the context of 


\section{Why is Adoption Like a First Nations Feast?}

community life. Participants were well aware of multifaceted community needs, they spoke of the many ways Lax Kwalaam members continue to "fight for things to be better," and, they need resources from government to actualize these adoptions. If community members were to consider this adoption 'campaign,' as one participant remarked, what commitments would the government make for First Nation adoptions?

First Nation people here need to be convinced again because of all the negative things that happened. When I talk about your campaign to convince us that we can do this -- that we can look after our own -- I feel we need to have support.

Government commitment could be demonstrated through innovative efforts to acknowledge community adoption inquiries. One participant spoke of the need for "a lot more encouragement from MCFD to put [adoptions] out to the First Nation communities". Participants also spoke of the need for government to assist villages with adoption support rather than expecting villages to attempt to understand adoption dynamics solely on their own.

Government commitment could include government initiated, internal, systematic changes for an adoption process more inclusive of Aboriginal people and their culture. Specifically, the need for systemic support must include "encouragement, openness and initiative" on the part of the government before, during and after the adoption process.

Government commitment could include symbols and actions to confirm the sincerity of an Aboriginal adoption focus. Participants discussed the present lack of Aboriginal adoption recruitment initiatives and wondered if this was an indication of government disinterest in Aboriginal adoptions. Some participants expressed uncertainty regarding the authenticity of government's interest in recruiting First Nation people as potential adopters. "My question is, are they [MCFD] looking for us to adopt? From what I see, I don't think they are. A lot of kids are going into the system".

\section{User-Friendly Adoption Information Systems}

\section{"Let the people know"}

Rather than mainstream recruiting through adoption messages constructed by non-Aboriginals, the adoption recruitment message participants recommended is one which is created and delivered by First Nation people. Adoption invitations could be continuous, friendly, hopeful, and include community adoption information groups, television and radio advertisements, and culturally appropriate adoption books centered on a First Nation values.
User-friendly adoption information includes adoption concepts presented in a relaxed, comprehensible manner to Aboriginal people. Community members often receive information in person; adoption information would be more successfully communicated in person. One participant stated, "You need to communicate, not just have some brochures sitting in the Health Unit, but have a personal representative coming and talking to the people in the community about the need for people to step forward." Valuable information is shared through story telling. Some participants wondered why they rarely heard of successful adoption stories of children in care. Some participants spoke of the need for positive First Nation adoption stories shared by First Nation adoptive parents.

Within the First Nation community, there is a need to offer frequent opportunities to members to consider adoption through comprehensive knowledge for their adoption decision. The recommendations were to provide adoption information groups so the community could clearly understand the adoption process, their legal rights and responsibilities, including single adopters, medical information, work benefits, successful age combinations for children entering into a family, family adjustment trends, and support around negative adoption responses. To further encourage adopters, adoption stories need to be shared to a larger audience of Aboriginal people.

Participants spoke of the value of Aboriginal adoptive parents sharing positive adoption stories through brief television ads, preferably on Aboriginal television networks. "Get out there and do more advertising." The invitation should include the delivery of Aboriginal children in care facts and a means to access adoption support.

\section{Consensual Practice > Colonial Policies}

\section{"Change policy to Accommodate First Nations families"}

Participants consider current adoption policy inadequate due to Eurocentric, colonial philosophies guiding adoption procedures. Participants stated the present adoption approach is dictated and directed to the First Nation community. Participants recommended mandated adoption policies follow a consensual model involving First Nation family, community and government decision-makers. "Cooperatively work out policy with First Nation people," stated one participant. A collaborative process in First Nation adoptions would require policy change to accommodate flexible cultural needs of families. Participants spoke of policy demanding their "mandatory participation", even in the midst of challenging situations, and widespread social worker efforts for solutions within family before adopting their children to "outsiders." 
Family information is critical in order for First Nation people to consider adoption. Participants identified the amount of family and cultural information obtained for Aboriginal children is severely limited. First Nation families do not know who the child is connected with and the current policy for collecting family and cultural information prevents First Nation adopters from coming forward. Participants recommended that more accurate family and cultural information be obtained from the system prior to contacting potential adopters. One participant indicated that when children were in the "system too long" their family information was lost. "They're not looking after the best interest of the child, not in our culture", stated one participant.

Participants felt the role of the family is not recognized within the adoption system, and yet the family role is critical in First Nation culture. "Family first" stated one participant. In this regard the opportunity for regular birth family contact is of primary importance, and should be agreed on before adoption finalization. Not only did participants see the lack of connection with the birth parents in adoption as problematic, but they indicated that the grandparents, aunts and uncles were overlooked as well. One participant stated that the adoption process should assist in, "gathering the family together... it would really help them [birth family] to get through the process." "I feel if we don't take people from our culture and extended family, it would be better if we could go back to operating more as a community."

Several policies changes were suggested, "family-bloodlines" could to be stored on a government system for each child in care; the numbers of children available for adoption clearly tracked for each Aboriginal community; and pre and post-adoption stages updated with community leaders. The adoption process needs to progress to one where the grief and loss of the birth family and adoptive family has "flexible boundaries."

\section{Social Work Cultural Training Needed}

\section{[Social workers]... "feel comfortable with the people you're dealing with!"}

Social workers are often placed in the 'expert' role. With time and work responsibilities, the flexibility to enter into the learner role can lessen, and it is precisely the learner mind-set that is needed to gain cultural understanding when working with First Nation communities. The social worker sees systemic flaws, but often has few leadership resources to initiate change.

The poor outcomes that are evident in the current lived experiences of Aboriginal children, youth, and families compel child welfare to move past tinkering with services to examine what needs to be changed in the values and basic approach of the profession itself to improve child welfare and relationships with Aboriginal children and families (Blackstock, Brown \& Bennett, 2007, p. 64).

Adoption often displays the end result of many years of MCFD planning and intervention. The energy and values of social workers are reflected in their work with families and communities. Often as final reports are written describing the child's history, the social workers involved in this stage see the end result of systematic procedures, multiple foster placements and cultural omission. To catch the light for change as early in the process as possible, and continue past numerous obstacles, leadership and learning must unite. 3

To counteract the continuance of negative adoption experiences, a more personable approach with First Nation people is desired; Circle group participants recommend social workers establish strong relationships with local First Nation leaders. Circle group participants described social workers as authoritarian, professionals who remove children thereby assisting in the disassociation of children from their community, rather than supporting families. Overall the lack of cultural understanding by social workers frustrates First Nation people. Another participant asked for power balance in the relationship stating "take away the fear [that First Nations people have of the] authority that social workers have ... the feeling that people have that social workers have all the control." Yet another participant said she wanted "openness, mutual understanding" and a social worker who could be "not so bashful" and "relaxed" when working with them. One participant said she wanted to build up a positive working relationship with social workers rather than having a "crisis relationship" generated around problem solving during emergencies.

First Nation adoption is related to families, who are intractably connected to culture. Participants wanted to feel respected by social workers. "You have workers who don't know ... That child's culture is its clan, its tribe, its community. There's a lot of protocol you need to know.' In order to begin to understand the culture, participants recommend that social workers engage in experiential learning of First Nation culture by participating in feasts or by visiting the First Nation communities for a few days prior to meetings. One participant challenged social workers to be open to learn about Aboriginal culture in the same way that First Nation people have to learn about other cultures, including other First Nation cultures. "We

3 Social workers can feel adequate in their role, as did I. My thesis supervisor confronted my awkwardness as a learner and ushered me towards a renewed learning attitude. Leaders from Lax Kw'alaam instructed me to listening to gather information thereby optimized this unique cultural experience. The dichotomy of First Nation cultural needs and the academic requirements combined to further challenged me to new levels as a learning leader. The Royal Roads University Leadership program provided essential tools to engage in a creative, open, innovative approach to this adoption research. 


\section{Why is Adoption Like a First Nations Feast?}

are quite accustomed to dealing with anybody and everybody" and participants spoke of how they watch and learn from other First Nation people in order to build relationships. Participants stated that attending cultural events should be mandatory, even in consideration of busy workloads. The development and maintenance of culturally skilled social workers should be supported within the government structure.

Social work cultural training should be extended to the university level (MacDonald \& MacDonald, 2007). Participants discussed the need for cultural skills and information to begin at the university level for social workers. One participant recommended that experiential cultural learning should become a mandatory skill for educational credentials.

How do social workers acquire leadership? Not only do leadership opportunities need to be developed through practice, but leadership skills need to be taught at the university level.

Many universities proclaim that one of their most important missions is to train young men and women to be the leaders of the next generation. If they are serious about that proposition, they must be serious about the study of leadership and leadership development... But responsibility for strengthening leadership studies does not fall solely upon university administrators; if anything, it falls more heavily upon scholars and practitioners in the field, for they must build and solidify the intellectual foundations (Gergen \& Kellerman, 2003, p. 25).

Is there a way for government to require social workers to have leadership training before they enter the field?

\section{Feast metaphor}

\section{"They belong to us"}

Feasts were described by participants as being a time of family connection and joy. Participants described families serving together, honoring traditions, and delighting in being part of a collective celebration which includes eating and dancing together. At feasts, the strength of children is acknowledged and their identity confirmed. In addition, feasts are a means of announcing the child's "Indian name" to be received and maintained as historical community information.

Participants discussed a new adoption approach which could involve a feast, similar to the celebration feast signifying the arrival of an infant to the community. The baby welcoming feast is spoken often in the Smalayx language to mean, 'You are ours.' The feast could include a child receiving a new adoptive name. An adoption feast could bring the community together so adoption information and stories could be heard by the community without the appearance of secrets or deceptive adoption agreements.

\section{Conclusion}

Aboriginal people, who suffered family disassociation at the hands of social workers, have imparted to us recommendations for adoption changes. What will be done with such wisdom? We can continue to work diligently inside our present structure, or we can attempt to push forward and break new ground for the benefit of adopted Aboriginal children (MacDonald, Glode \& Wein, 2005).

Challenges to the paradigm of historical child welfare and adoptions practice are already being initiated by Indigenous leaders, such as Dr. Joan Glode, C.M. who together with the First Nations Child \& Family Caring Society of Canada and the Assembly of First Nations, filed a Canadian Human Rights complaint in 2008 alleging that the Government of Canada was discriminating in providing less funding for Aboriginal child welfare than for non-Aboriginal child welfare (MacDonald, 2010). Dr. Glode received the Order of Canada in 2009 for her leadership and devotion to the social welfare of aboriginal children and families and remains an active voice as a Mi'Kmag First Nation community member of the Acadia (Band) in Nova Scotia.

Social workers have latitude in how they maintain cultural dignity for Aboriginal families through their daily practice. Social workers can, for example, lead-the-way by advantageously gathering specific birth family and cultural information, thereby increasing adoption opportunities for children. Social workers with courageous hearts and determined wills long for a new era of adoption, leadership skills (Bolman \& Deal, 2003) offer valuable resources to engage in continual learning amidst the daily complexities of government procedures and fiscal restraints.

\section{References}

Adoption Act, Copyright U.S.C. (1996). Retrieved February 1st, 2007 from http://www.qp.gov.bc.ca/statreg/stat/A/96005_01.htm\#section3

Assembly of First Nation (2009). Retrieved October 24, 2009, History of Indian Residential Schools. Available online at http://www.afn.ca/ residentialschools/history.html.

Bagley C, Young L, Scully A. (1993). International and transracial adoptions: A mental health perspective. Northern Social Work Practice, Northern and Regional Studies Series; 4: 116-35.

Bennett, M. (2004). A review of the literature on the benefits and drawbacks of participatory action research. First Peoples Child \& Family Review, 1(1), 19-32. Retrieved August 21, 2007 from http://www.fncfcs.com/pubs/ vollnum1/Bennett_pp19-32.pdf. 


\section{First Peoples Child \& Family Review, Volume 5, Number 1, 2010}

Bennett, M., Blackstock, C. \& DeLaRonde, R. (2005). A literature review and annotated bibliography on aspects of child welfare in Canada ( $2 n d E d$.). First Nation Research Site of the Center of Excellence for Child Welfare and the First Nation Child \& Family Caring Society of Canada. Retrieved August 31, 2007 from http://www.fncaringsociety.com/docs/ AboriginalCWLitReview 2ndEd.pdf.

Blackstock, C., Brown, I., \& Bennett, M. (2007). Reconciliation: Rebuilding the Canadian child welfare system to better serve aboriginal children and youth. In I. Brown, F. Chaze, D. Fuchs, J. Lafrance, S. McKay \& S. Thomas Prokop (Eds.), Putting a human face on child welfare: Voices from the prairies. (pp. 59-87). Canada: Prairie Child Welfare Consortium; Center of Excellence for Child Welfare. Retrieved August 24, 2007 from http://www.cecw-cepb.ca/files/file/prairebook.

Bolman, L., D., \& Deal, T., E. (2003). Reframing organizations: Artistry, choice and leadership (3rd ed.). California, USA: Jossey-Bass.

Carriere, J. (2005). Connectedness and health for first nation adoptees. (Doctor of Philosophy, Department of Human Ecology, University of Alberta), pp i-249. (00061833)

Carriere, J. (2007). Promising practice for maintaining identities in first nation adoption. First Peoples Child \& Family Review, 3(1), pp. 46-64. Available online at http://www.fncaringsociety.com/pubs/vol3numl/ Carriere_pp46.pdf.

Child, Family and Community Service Act, (1996). [RSBC 1996] Copyright. Queen's printer, Victoria, BC, Canada. Retrieved on February 1st, 2006 from http://www.qp.gov.bc.ca/statreg/stat/C/96046 01. htm\#section 4

Collier, F. (2002). Good practice in adoption. In Douglas, Anthony (Ed), Adoption: Changing Families, Changing Times. (pp. 52-56). Florence, KY, USA.

Corbett, J. (2002). Recruiting parents for hard-to-place children. In Douglas, Anthony(Ed), Adoption: Changing Families, Changing Times. (pp. 39-40) Florence, KY, USA

Crichlow, W. (2003). Western colonization as disease: Native adoption and cultural genocide. Canadian Social Work, 5(1), pp. 88-107.

Dave Thomas Foundation for Adoption Canada. (2005). Adoption in Canada - A Report on Public Opinion. Summary of August 2004 survey by Ipsos-Reid, commissioned by the Dave Thomas Foundation for Adoption Canada.

Fogg-Davis, H. (2002). The ethics of transracial adoption. USA: Cornell University Press.

Fournier, S., \& Crey, E. (1997). Stolen from our embrace: The abduction of first nations children and restoration of aboriginal communities. Vancouver, BC: Douglas \& McIntyre.

Gergen, D \& Kellerman, B. (2003). Public Leaders: Riding a New Tiger: In Donahue, John D.(Ed), For the People?: Can We Fix Public Service? (pp. 13-25). Washington, DC, USA: Brookings Institution Press. Retrieved August 26, 2007 from http://site.ebrary.com/lib/royalroads/ Doc?id=10063880\&ppg=27.

Giesbrecht, T. (2004). Adoption. In Bala, N., Zapf, M. K., Williams, R. J., Vogl R. \& Hornick J. P. (Eds.), Canadian child welfare law: Children, families and the state. Toronto, Canada: Thompson Educational Publishing.

Glesne, C. (2006). Becoming qualitative researchers: An introduction (3rd Edition). Boston, USA: Pearson Education.
Halverson, K., Puig, M., E., \& Byers, S., R. (2002). Culture loss: American Indian family disruption, urbanization and the Indian child welfare act. Child Welfare, 81(2), pp. 319-336. Retrieved August 26, 2007, from https://ezproxy.royalroads.ca/login?url=http://search.ebscohost.com. ezproxy.royalroads.ca/login.aspx?direct $=$ true $\& \mathrm{db}=s i h \& A N=6635155$ \&site $=$ ehost-live.

Keewatin, D. (2004). An indigenous perspective on custom adoption. (Master in Social Work, Faculty of Social Work, University of Manitoba), pp. i-124

MacDonald, N. (2010). We are not the savages: First nation history by Daniel N. Paul. Retrieved April 19th, 2010 from http://www.danielnpaul.com/ JoanGlode.html.

MacDonald, N., Glode, J., \& Wien, F. (2005). Respecting Aboriginal families pathways to resilience in custom adoption and family group conferencing. In M. Ungar (Ed.). Handbook for working with children and youth: Pathways to resilience across cultures and contexts, pp. 357-370. California, Sage.

MacDonald, N., \& MacDonald, J. (2007). Reflections of a Mi'Kmaq social worker on a quarter of a century work in First Nations child welfare. First Peoples Child \& Family Review, 3(1), pp. 34-45. Retrieved on April 19th, 2010 from http://www.fncaringsociety.com/pubs/vol3numl/ MacDonald_MacDonald_pp34.pdf.

National Council of Welfare. (2007). First nation, Métis and Inuit children and youth: Time to act. No. HS54-1/2007E-PDF). Ottawa, Ontario, Canada: Retrieved November 16, 2007 from http://www.ncwcnbes.net/ documents/researchpublications/ResearchProjects / FirstNationsMeti sInuitChildrenAndYouth/2007Report-TimeToAct/ReportENG.pdf

Riggs, D. (2003). ACC strives to help Canada's waiting children. From the Spring 2003 "Adoptalk", by the North American Council on Adoptable Children; Retrieved February 25th, 2008, from http://www. canadaswaitingkids.ca/diana_riggs_article.html

Sinclair, R. (2007). Identity lost and found: Lessons from the sixties scoop. First Peoples Child \& Family Review, 3(1): 65. Retrieved Jan 25th, 2007 from http://www.fncaringsociety.com/pubs/vol3num1/ Sinclair_pp65.pdf.

Snow, R., \& Covell, K. (2006). Adoption and the best interests of the child: The dilemma of cultural interpretations. The International Journal of Children's Rights, 14: 109-117.

Strauss, A., \& Corbin, J. (1998). Basics of qualitative research: Techniques and procedures for developing grounded theory. (2nd Edition). California, USA: Sage Publications Inc.

Stringer, E., T. (1999). Action research (3rd Edition). USA: Sage Publications.

Timpson, J. (19995). Four decades of literature on native Canadian child welfare: Changing themes. Child Welfare, 74(3): 525-546.

Webber, M. (1998). As if kids mattered: What's wrong in the world of child protection and adoption. Toronto, Canada: Key Porter Books.

Wein, F., Blackstock, C., Laxley, J., \& Trocme, N. (2007). Keeping first nation children at home: A few federal policy changes could make a big difference. First Peoples Child \& Family Review, (3)1, pp. 10-14. Retrieved on April 19th, 2010 from http://www.fncaringsociety.com/pubs/ vol3numl/Wien_Blackstock_Loxley_Trocme_pp10.pdf. 